\title{
Country characteristics and acute diarrhea in children from developing nations: a multilevel study
}

\author{
Ángela María Pinzón-Rondón ${ }^{1,2^{*}}$, Carol Zárate-Ardila ${ }^{1}$, Alfonso Hoyos-Martínez ${ }^{1}$, Ángela María Ruiz-Sternberg ${ }^{1}$
} and Alberto Vélez-van-Meerbeke ${ }^{1}$

\begin{abstract}
Background: Each year 2.5 billion cases of diarrheal disease are reported in children under five years, and over 1,000 die. Country characteristics could play a role on this situation. We explored associations between country characteristics and diarrheal disease in children under 5 years of age, adjusting by child, mother and household attributes in developing countries.
\end{abstract}

Methods: This study included 348,706 children from 40 nations. We conducted a multilevel analysis of data from the Demographic and Health Surveys and the World Bank.

Results: The prevalence of acute diarrhea was $14 \%$. Country inequalities $(\mathrm{OR}=1.335 ; 95 \% \mathrm{Cl} 1.117-1.663)$ and country's low income $(\mathrm{OR}=1.488 ; 95 \% \mathrm{Cl} 1.024-2.163)$ were associated with diarrhea, and these country characteristics changed the associations of well-known determinants of diarrhea. Specifically, living in poor countries strengthens the association of poor household wealth and mother's lack of education with the disease. Other factors associated with diarrhea were female sex of the child $(O R=0.922 ; 95 \% \mathrm{Cl} 0.900-0.944)$, age of the child ( $\mathrm{OR}=0.978 ; 95 \% \mathrm{Cl}$ 0.978-0.979), immunization status ( $\mathrm{OR}=0.821 ; 95 \% \mathrm{Cl}$ 0.799-0.843), normal birthweight $(\mathrm{OR}=0.879 ; 95 \% \mathrm{Cl}$ 0.834-0.926), maternal age $(\mathrm{OR}=0.987 ; 95 \% \mathrm{Cl} 0.985-0.989)$, lack of maternal education $(\mathrm{OR}=1.416 ; 95 \% \mathrm{Cl} 1.283-1.564)$, working status of the mother $(\mathrm{OR}=1.136 ; 95 \% \mathrm{Cl} 1.106-1.167)$, planned pregnancy $(\mathrm{OR}=0.774 ; 95 \% \mathrm{Cl} 0.753-0.795)$, a nuclear family structure $(\mathrm{OR}=0.949 ; 95 \% \mathrm{Cl} 0.923-0.975)$, and household wealth $(\mathrm{OR}=0.948 ; 95 \% \mathrm{Cl} 0.921-0.977)$.

Conclusions: Inequalities and lack of resources at the country level in developing countries -but not health expenditure- were associated with acute diarrhea, independently of child, family and household features. The broad environment considerably modifies well-known social determinants of acute diarrhea and public health campaigns designed to target diarrhea should consider macro characteristics of the country.

\section{Background}

In spite of global efforts to improve child health, millions of children under the age of five die mostly from preventable causes, including 6.6 million in 2012 [1]. The majority of these deaths occurred in developing countries, predominantly in Asia, Africa and Latin America [2]. Pneumonia is the leading cause of death in this age group, followed by diarrheal disease, which

\footnotetext{
* Correspondence: angela.pinzon@urosario.edu.co
'Escuela de Medicina y Ciencias de la Salud, Universidad del Rosario, Bogotá,

*Correspondence: angela.pinzon@urosario.edu.co
'Escuela de Medicina y Ciencias de la Salud, Universidad del Rosario, Bogotá, Colombia

${ }^{2}$ Facultad de Medicina, Universidad del Rosario sede Quinta de Mutis, Carrera 24 \#63C-69, Bogotá, Colombia
}

causes $9 \%$ of the fatalities [1]. Each year 2.5 billion cases of diarrheal disease are reported in children under 5 years, and on average every day over 1,400 children die $[1,2]$. According to UNICEF and the World Health Organization (WHO), the fight against pneumonia and diarrhea, along with nutritional reinforcement, could save millions of children [3]. In developed nations mortality secondary to diarrhea in this age group is very low and the disease's great economic cost is the main concern. In contrast, in developing countries, diarrhea's burden is mainly the loss of human capital due to its high mortality rate [4]. The control of diarrheal disease is imperative in order to decrease mortality in children under 
5 years of age and achieve development goals [3]. Information on the disease is needed in order to develop mechanisms to decrease its morbidity and mortality.

A review of factors associated with acute diarrhea was conducted searching in two electronic databases, PubMed and EMBASE. The search methodology is included in Appendix 1. Individual, family and household characteristics have been implicated in the incidence of diarrhea $[3,5,6]$. Most of these associations have been established through studies developed primarily in industrialized nations [5] or limited to specific geographic regions [7-11]. Following Bronfenbrenner's ecological model, the factors that have been associated with diarrheal disease by individual characteristics and environmental systems are presented below [12]. The child factors that have been associated with diarrhea are young age [11], sex [10], absence of, or short term breastfeeding $[6,9,11]$, incomplete immunization schedule $[6,9]$, moderate to severe undernutrition $[6,9,11]$, lack of access to health care $[3$, 9], and low birthweight [6]. The family and household characteristics that have been related to diarrhea are lack of maternal education [3], maternal employment [3, 9], lack of sanitation [3, 9-11], nontraditional family structures [10], young maternal age [10], poverty [3], residence in rural areas [3], and household overcrowding [3]. Finally, researchers have found heterogeneity across countries in regards to the prevalence of diarrhea, suggesting that the social and economic context at the country level play a role in the incidence of the disease [13].

This paper explores, through multilevel methods, how country characteristics in developing countries from all geographic areas may be fundamental determinants of diarrheal disease, adjusting for known individual, family and household characteristics. It presents the association of country's wealth (per capita GDP), income inequality (GINI coefficient) and health expenditure, with diarrheal disease in children under 5 years of age from 40 developing countries.

\section{Methods}

\section{Data sources}

We designed a cross-sectional, transnational and multilevel study that used level-1 data (child, mother and household characteristics) from the Demographic and Health Survey (DHS) phase-V [14] and level-2 data (country characteristics) from the World Bank (WB) country data [15].

The DHS phase-V collected data from 41 developing countries from 2004 to 2010 . A nationally representative, probabilistic sample including rural and urban areas was collected from each participating country. Respondents were selected through a multistage, stratified sampling procedure of households. Between 5,000 and 30,000 households were surveyed per country. Data was gathered for the following countries: Albania 2008-2009, Azerbaijan 2006, Bangladesh 2007, Benin 2006, Bolivia
2008, Cambodia 2010, Colombia 2010, Congo 2005, Egypt 2005-2006, Philippines 2008, Ghana 2008, Guyana 2009, Haiti 2005-2006, Honduras 2005-2006, India 2005-2006, Indonesia 2007, Jordan 2007, Kenya 20082009, Lesotho 2009, Liberia 2007, Madagascar 2008-2009, Malawi 2010, Maldives 2009, Mali 2006, Namibia 20062007, Nepal 2006, Niger 2006, Nigeria 2008, Pakistan 2006-2007, Peru 2004-2008, Democratic Republic of Congo 2007, Dominican Republic 2007, São Tomé é Príncipe 2008-2009, Sierra Leone 2008, Swaziland 20062007, Tanzania 2010, East Timor 2009-2010, Ukraine 2007, Uganda 2006, Zambia 2007 and Zimbabwe 20052006. We excluded Ukraine from the analysis because the country did not apply the child health module of the survey. Information from the remaining 40 countries was merged to create a single dataset, which included 395,485 households with children. The dataset was further limited to biological mothers answering the survey to assure comparability $(384,662)$, living children $(359,527)$, permanent household residents $(349,849)$ and cases with complete information $(348,706)$.

After careful analysis, we concluded that the WB country data was the best source of level- 2 data in this study because of its country comparability and robustness when compared to data from other sources. These data included the 2010 indicators: per capita gross domestic product (GDP), Gini-coefficient, and health expenditure as a percentage of GDP.

\section{Outcome measures}

Diarrheal disease: presence of diarrhea (as defined by the respondent, the child's mother) at any time during the 2 weeks preceding the interview $(0=$ no; $1=$ yes $)$. Diarrhea was defined by DHS to the mothers as increased frequency of depositions and/or low consistency of feces. DHS does not distinguish by severity or number of episodes.

\section{Variables}

We divided the variables according to the data source: level-1 variables included the child, mother and household characteristics, and level-2 variables included country data. Initially we considered three levels of analysis -child, household and country- but most households had only one child under the age of five, so it was decided to include only one child per household, the youngest, and conduct a two-level analysis.

Level-1 data, children: sex coded as $0=$ male and $1=$ female, age of child in months, immunization defined as completeness of WHO schedule, coded as $0=$ incomplete and $1=$ complete, duration of breast feeding in months, possession of health card coded as $0=$ no and $1=$ yes, undernutrition defined as a BMI (body mass index) under the 5th percentile, and birthweight codified in dummy variables as follows: normal -above $2,500 \mathrm{~g}-0=$ no, 
$1=$ yes; low -below 2500 g- $0=$ no, $1=$ yes; and no weighted, $0=$ no, $1=$ yes. Although it is not ideal to include a birthweight missing indicator, taking into consideration that $46 \%$ of the children did not have this information, imputation was ruled out.

Level -1 data, mother: age in years, education: no education coded as $0=$ no, $1=$ yes; elementary education coded as $0=$ no, $1=$ yes; high school education coded as $0=$ no, $1=$ yes; superior [technical or professional] education coded as $0=$ no, $1=$ yes), current employment coded as $0=$ no and $1=$ yes and planned pregnancy referring to the pregnancy in which the index children was the outcome and coded as $0=$ no; $1=$ yes.

Level -1 data, household: number of household members defined as number of people living in the same home, place of residence coded as $0=$ rural and $1=$ urban, nuclear family defined as a social unit conformed exclusively by two parents and one or more children: $0=$ non-nuclear family, $1=$ nuclear family, sanitation score based upon water source and waste disposal, both classified as improved or unimproved, from zero to two, with higher grades indicating better sanitation [16], and wealth index calculated by the DHS considering income, possessions and quality of life, with higher grades indicating greater wealth. Wealth index ranges from 1 to 5 .

Level-2 data, country: Country wealth coded as a set of dummy variables as follows: Low income $(1=$ gross domestic product per capita (GDPpc) of US $\$ 1,025$ or less), Lower middle income ( $1=$ GDPpc between US $\$ 1,026$ and US $\$ 4,035)$, Upper middle income $(1=$ GDPpc between $\$ 4,036$ and $\$ 12,475)$, and High income ( $1=$ GDPpc of $\$ 12,476$ or more) [15], Inequality based on the Gini coefficient ( $1=$ top $25 \%$ unequal countries and $0=$ more equal countries) and health expenditure coded as a set of dummy variables based on the percentage of GDP expended on health. Low health expenditure $(1=5 \%$ or less), Middle health expenditure $(1=$ between 5.1 and $10 \%)$, High health expenditure $(1=$ more than $10 \%)$. We considered in the initial models country homicide rates and total country population, but these variables were omitted in the final models because of their lack of association with diarrheal disease and their negative effects on the model's validity, measured using residual files and reliability estimates.

\section{Statistical analysis}

The analysis was conducted considering known factors associated with diarrhea and the country characteristics to study. Multilevel analyses were preferred because the hierarchical nature of the data violated the principles of independence and homogeneity required for a singlelevel analysis [17]. Country characteristics were shared by many children.
All the variables were used in the initial analysis. Afterwards, sanitation and number of members in the household were excluded due to co-linearity. The wealth index was built considering both variables. Possession of a health card and undernutrition were excluded for their co-linearity with immunization and wealth index, respectively. Although low BMI has been highly associated with diarrhea, wealth index was used over undernutrition in the models because the former had $35 \%$ of its data missing.

The statistical analysis was performed using SPSS 20.0 (IBM) and HLM 7 (Scientific Software International, Inc.), as follows: 1) we merged the individual datasets of the 40 countries, 2) we calculated descriptive statistics for categorical (proportions) and numerical variables (mean, standard deviation, minimum and maximum values), 3) we obtained bivariate odd ratios using hierarchical linear modeling logistic regressions of diarrheal disease in all of the studied variables, and 4) we generated multivariable models for diarrhea using hierarchical linear modeling. Stepwise multilevel logistic regression equations were estimated. Individual, family and household factors were included as possible predictors of diarrhea, and differences were deemed to be significant with $P$-value less than 0.05 . The large sample size allowed us to find small differences with narrow $95 \%$ confidence intervals. Finally, multilevel modeling was used to explore the association of country characteristics with diarrheal disease (between countries associations) adjusting for individual, family and household predictors of the condition (within countries associations) [18, 19]. Full maximum likelihood was used to fit the models. Random effects were estimated only for indicators with variations between groups that could be explained by the studied variables, allowing the coefficients to vary across groups. Those level-1 indicators were centered on the country mean to avoid the problem of co-linearity. All other variables, as well as the neighborhood variables, were centered on the grand mean and we constrained their variance. The final model can be seen in Appendix 2 . We have calculated median odd ratios (MORs) and intra-class correlations (ICC) for the models, as well as $80 \%$ interval odd ratios (IORs) for the country level variables $[20,21]$.

We tested bivariate interactions by multiplying duration of breast feeding and maternal education, duration of breast feeding and maternal employment, immunization and maternal education, and wealth index and immunization to determine if an interaction was present.

Within countries, weights provided by the DHS for children under 5 years of age were utilized in the analysis for the level 1 data. The weights were adjusted to the survey design. Post-stratification was incorporated as a weight adjustment. The adjusted weights were used in 
all of the analyses. For level 2 data, between countries, weights were created and used in the analysis for each country accounting for the country's population.

Regression analyses considering the DHS year of survey were performed to assure that the results were not biased by the different time lapses the surveys took place at each country.

Macro International provided the datasets from the 41 countries included in this study. The study was based on secondary sources without identifying information about individual participants. It was given approval by the institutional review board, Comité de Ética en Investigación, Universidad del Rosario.

\section{Results}

\section{Descriptive statistics}

The final sample included 348,706 children under 5 years of age from 40 developing nations. Figure 1 presents the prevalence of diarrheal disease in each of the studied countries. The descriptive characteristics of the study population are shown in Table 1 . The complete dataset had an even child gender distribution, and the average age of the children was 29 months. The overall prevalence of diarrhea in the 2 weeks preceding the survey was $14 \%$.

Only $58 \%$ of the children were up-to-date on their immunization schedule, and $84 \%$ had a health card.
Approximately half (48\%) of the children had normal birthweight, and $6 \%$ were undernourished. The children were, on average, breastfed for 14 months.

Almost a third of the mothers did not have education (30\%), half of them were employed, and $70 \%$ reported a planned pregnancy. Most households (65\%) were located in rural areas, with an average number of seven inhabitants, and most of them (69 \%) had a nuclear structure.

\section{Bivariate logistic regressions}

Results of the bivariate regression analysis are shown in Table 2.

\section{Multivariable logistic regressions}

The results of logistic regression for diarrheal disease are presented in Table 3. After controlling for all of the study variables we found that both country-level low income and country-level inequality were positively associated with diarrhea. Health expenditure did not have a significant association with diarrhea.

After data analysis the following child factors were associated with the onset of diarrheal disease: female gender, age, immunization and normal birthweight. The maternal factors negatively associated with diarrhea were age and planned pregnancy. The maternal factors positively associated with diarrhea were lack of education,

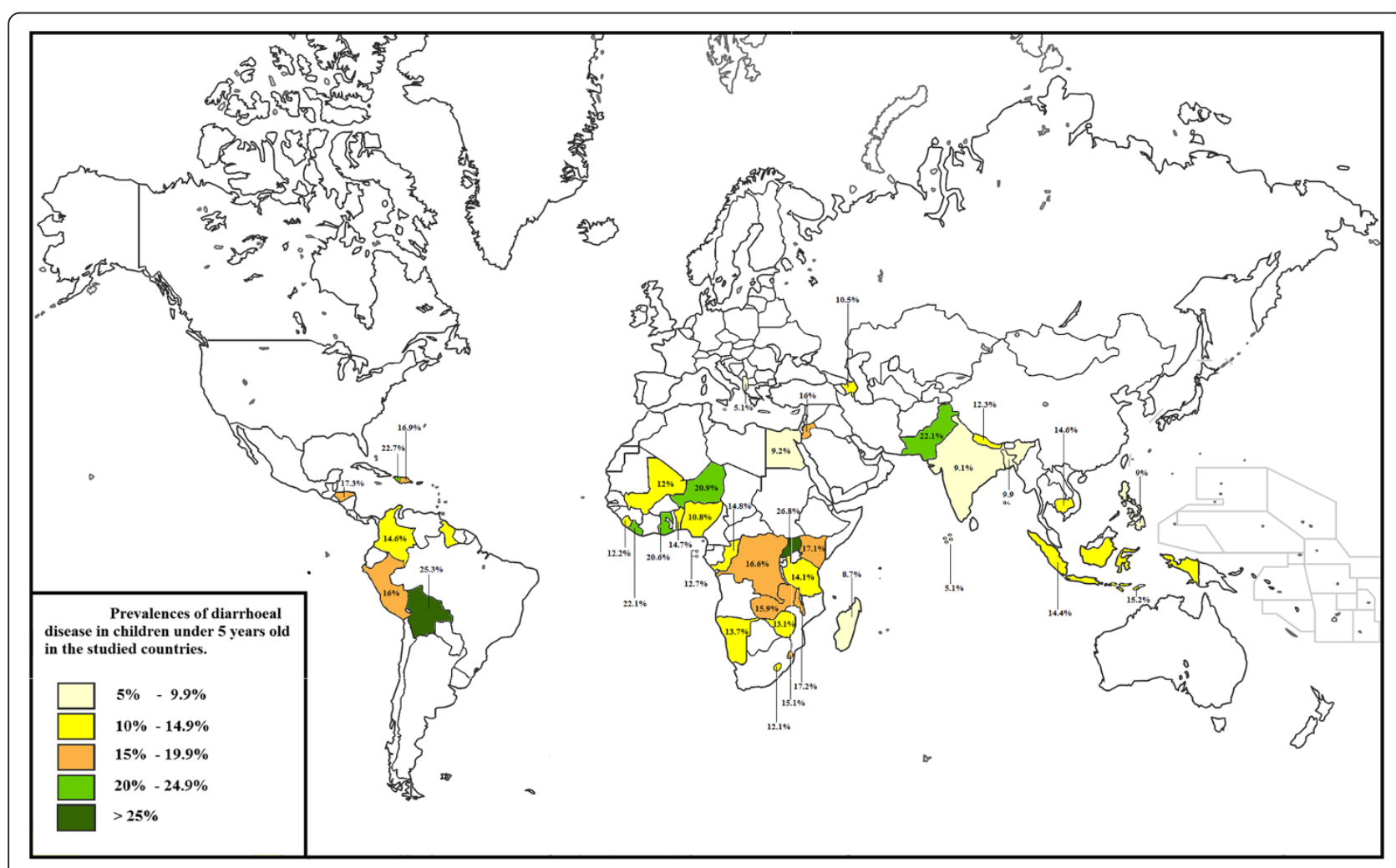

Fig. 1 Prevalences of diarrhocal disease in children under 5 years old in the studied countries 
Table 1 Descriptive statistics. Proportions of categorical variables and mean/standard deviation of numerical variables children from 40 countries, 2004-2010

\begin{tabular}{|c|c|c|c|}
\hline Variable & Proportion & Mean & SD \\
\hline \multicolumn{4}{|l|}{ Children } \\
\hline Diarrheal disease & 0.14 & & \\
\hline Female sex & 0.49 & & \\
\hline Age of child (months) & & 28.76 & 17.25 \\
\hline Immunization & 0.58 & & \\
\hline Possession of health card & 0.84 & & \\
\hline Undernutrition & 0.06 & & \\
\hline Normal birth weight & 0.48 & & \\
\hline Low birth weight & 0.06 & & \\
\hline No weighed at birth & 0.46 & & \\
\hline Duration of breastfeeding (months) & & 13.73 & 9.86 \\
\hline \multicolumn{4}{|l|}{ Mother } \\
\hline Age of mother (years) & & 28.66 & 6.72 \\
\hline No education & 0.30 & & \\
\hline Elementary education & 0.33 & & \\
\hline High school education & 0.30 & & \\
\hline Superior education & 0.07 & & \\
\hline Employment & 0.50 & & \\
\hline Planned pregnancy & 0.70 & & \\
\hline \multicolumn{4}{|l|}{ Household } \\
\hline Number of household members & & 6.59 & 3.2 \\
\hline Sanitation & & 1.24 & 0.74 \\
\hline Urban residence & 0.35 & & \\
\hline Nuclear family & 0.69 & & \\
\hline Wealth index & & 3.00 & 1.41 \\
\hline \multicolumn{4}{|l|}{ Country data } \\
\hline Low income & 0.48 & & \\
\hline Lower middle income & 0.35 & & \\
\hline Upper middle income & 0.18 & & \\
\hline Inequalities & 0.25 & & \\
\hline Low health expenditure & 0.33 & & \\
\hline Middle health expenditure & 0.63 & & \\
\hline High health expenditure & 0.08 & & \\
\hline
\end{tabular}

elementary education and high school education (as compared with superior education) and maternal employment. Household factors negatively associated with the disease were a nuclear family structure and wealth. The between countries variations were evaluated using the variances. Variables that presented statistically significant between-countries variances were immunization status, maternal education, and household wealth. Only the country variances of lack of maternal education on diarrhea ( $p$-value <0.001) and household wealth on
Table 2 Bivariate regressions of acute diarrheal disease on independent variables

\begin{tabular}{|c|c|c|c|}
\hline Variable & OR & $\mathrm{Cl}$ & $P$-value \\
\hline \multicolumn{4}{|l|}{ Children } \\
\hline Female sex & 0.923 & $0.901,0.946$ & $<0.001$ \\
\hline Age (months) & 0.978 & $0.976,0.981$ & $<0.001$ \\
\hline Immunizations & 0.824 & $0.801,0.838$ & $<0.001$ \\
\hline Duration of breastfeeding (months) & 0.989 & $0.985,0.992$ & 0.026 \\
\hline Possession of health card & 0.723 & $0.604,0.842$ & $<0.001$ \\
\hline Underweight & 1.091 & $1.069,1.109$ & $<0.001$ \\
\hline \multicolumn{4}{|l|}{ Infant birth weight } \\
\hline Normal birth weight & 0.904 & $0.868,0.923$ & $<0.001$ \\
\hline Low birth weight & 1.022 & $1.080,1.199$ & 0.003 \\
\hline No weighed at birth & 1.064 & $1.046,1.109$ & $<0.001$ \\
\hline \multicolumn{4}{|l|}{ Mother } \\
\hline Age of mother (years) & 0.978 & $0.972,0.984$ & $<0.001$ \\
\hline \multicolumn{4}{|l|}{ Maternal education } \\
\hline No education & 1.119 & $1.086,1.151$ & $<0.001$ \\
\hline Elementary education & 1.087 & $1.056,1.118$ & $<0.001$ \\
\hline High school & 0.931 & $0.901,0.963$ & $<0.001$ \\
\hline Superior education & 0.649 & $0.609,0.701$ & $<0.001$ \\
\hline Employment & 1.011 & $0.984,1.033$ & 0.632 \\
\hline Planned pregnancy & 0.727 & $0.709,0.752$ & $<0.001$ \\
\hline \multicolumn{4}{|l|}{ Household } \\
\hline Number of household members & 1.011 & $1.007,1.014$ & 0.002 \\
\hline Urban residence & 0.661 & $0.851,0.899$ & $<0.001$ \\
\hline Nuclear family & 0.880 & $0.861,0.906$ & $<0.001$ \\
\hline Sanitation & 0.901 & $0.887,0.921$ & $<0.001$ \\
\hline Wealth index & 0.918 & $0.911,0.928$ & $<0.001$ \\
\hline \multicolumn{4}{|l|}{ Country } \\
\hline \multicolumn{4}{|l|}{ Country level income } \\
\hline Low income & 1.257 & $1.041,1.676$ & $<0.001$ \\
\hline Lower middle income & 0.881 & $0.653,1.172$ & 0.400 \\
\hline Upper middle income & 0.803 & $0.562,1.149$ & 0.096 \\
\hline Inequality & 1.232 & $1.012,1.609$ & 0.043 \\
\hline \multicolumn{4}{|l|}{ Country level health expenditure } \\
\hline Low health expenditure & 0.858 & $0.641,1.137$ & 0.295 \\
\hline Middle health expenditure & 1.118 & $0.843,1.498$ & 0.442 \\
\hline High health expenditure & 1.089 & $0.730,1.631$ & 0.745 \\
\hline
\end{tabular}

$P<0.05, P<0.01, P<0.001, P<0.0001$

diarrhea ( $p$-value $<0.001)$ were in part explained by the country variables (low income country). All other interactions were non-significant (see Table 4). The Median Odds Ratios (MORs) were 1.51 for model 1 and 1.43 for model 2.

Living in poor and unequal countries increases the magnitude of the association of lack of maternal education 
Table 3 Adjusted odds ratio (OR) for diarrheal disease associated with individual and country level characteristics among children under 5 years from developing countries calculated using an HLM multivariate multilevel logistic regressions population average fixed effects

\begin{tabular}{|c|c|c|c|c|c|}
\hline \multirow{2}{*}{$\begin{array}{l}\text { Reliability } \\
\text { Variables }\end{array}$} & \multicolumn{2}{|c|}{$\begin{array}{l}\text { Model 1. Adjusted for children, } \\
\text { mother and household characteristics } \\
99 \%\end{array}$} & \multicolumn{2}{|c|}{$\begin{array}{l}\text { Model 2. Adjusted for model } 1 \\
\text { and for country characteristics } \\
99 \%\end{array}$} & \multirow[t]{2}{*}{$80 \%$ IOR } \\
\hline & OR & $\mathrm{Cl}$ & OR & $\mathrm{Cl}$ & \\
\hline \multicolumn{6}{|l|}{ Level-1 } \\
\hline \multicolumn{6}{|l|}{ Children } \\
\hline Female sex & 0.923 & {$[0.902,0.944]$} & 0.922 & {$[0.900,0.944]$} & \\
\hline Age of the child (months) & 0.979 & {$[0.978,0.979]$} & 0.978 & {$[0.978,0.979]$} & \\
\hline Immunizations & 0.820 & {$[0.773,0.870]$} & 0.821 & {$[0.799,0.843]$} & \\
\hline \multicolumn{6}{|l|}{ Infant birth weight } \\
\hline Low birth weight & \multicolumn{2}{|c|}{ Reference category } & \multicolumn{2}{|c|}{ Reference category } & \\
\hline Normal weight at birth & 0.881 & {$[0.838,0.926]$} & 0.879 & {$[0.834,0.926]$} & \\
\hline No weighed at birth & 0.879 & {$[0.835,0.926]$} & 0.879 & {$[0.834,0.926]$} & \\
\hline Duration of breastfeeding (months) & 0.984 & {$[0.982,1.098]$} & 0.984 & {$[0.966,1.098]$} & \\
\hline \multicolumn{6}{|l|}{ Mother } \\
\hline Age of the mother (years) & 0.987 & {$[0.986,0.989]$} & 0.987 & {$[0.985,0.989]$} & \\
\hline \multicolumn{6}{|l|}{ Maternal Education } \\
\hline No education of the mother ${ }^{a}$ & 1.422 & {$[1.299,1.557]$} & 1.416 & {$[1.283,1.564]$} & \\
\hline Elementary education & 1.430 & {$[1.341,1.524]$} & 1.453 & {$[1.357,1.556]$} & \\
\hline High school education & 1.274 & {$[1.200,1.353]$} & 1.286 & {$[1.205,1.373]$} & \\
\hline Superior education & \multicolumn{2}{|c|}{ Reference category } & \multicolumn{2}{|c|}{ Reference category } & \\
\hline Employment & 1.135 & {$[1.106,1.165]$} & 1.136 & {$[1.106,1.167]$} & \\
\hline Planned pregnancy & 0.776 & {$[0.756,0.797]$} & 0.774 & {$[0.753,0.795]$} & \\
\hline \multicolumn{6}{|l|}{ Household } \\
\hline Nuclear family & 0.943 & {$[0.925,0.974]$} & 0.949 & {$[0.923,0.975]$} & \\
\hline Urban residence & 1.047 & {$[1.014,1.081]$} & 1.044 & {$[0.969,1.079]$} & \\
\hline Wealth Index & 0.950 & {$[0.922,0.972]$} & 0.948 & {$[0.921,0.977]$} & \\
\hline \multicolumn{6}{|l|}{ Level - 2} \\
\hline Country & & & & & IOR \\
\hline \multicolumn{6}{|l|}{ Country-level Income } \\
\hline Low income & & & 1.488 & {$[1.024,2.163]$} & {$[1.094,2.131]$} \\
\hline Lower middle income & & & 1.157 & {$[0.786,1.704]$} & {$[0.817,1.629]$} \\
\hline Upper middle income & & & \multicolumn{3}{|c|}{ Reference category } \\
\hline Inequality & & & 1.335 & {$[1.117,1.663]$} & {$[0.954,1.470]$} \\
\hline \multicolumn{6}{|l|}{ Country-level Health expenditure } \\
\hline Low health expenditure & & & \multicolumn{3}{|c|}{ Reference category } \\
\hline Middle health expenditure & & & 1.192 & {$[0.888,1.601]$} & {$[0.916,1.548]$} \\
\hline High health expenditure & & & 1.006 & {$[0.590,1.715]$} & {$[0.989,0.994]$} \\
\hline
\end{tabular}

"Since "No maternal education" is involved in an interaction, it is important to clarify that the OR presented in the table is the effect of "No maternal education" in countries with high GDP per cápita, no inequality and low health expenditure

Statistically significant ORs are reported in bold ( $P$ values $\leq 0.05$ )

with diarrhea. Living in poor countries increases the association between wealth and diarrhea.

When adding the interaction terms at the level 1 to the models, none of them - duration of breast-feeding and maternal education, duration of breast-feeding and maternal employment, immunization and maternal education, and wealth index and immunization- were statistically significant.

\section{Discussion}

This paper contributes to the study of the associations between country characteristics and child health. We 
Table 4 Interactions between individual and country level variables from multilevel regressions of child, mother, household and country characteristics on diarrheal disease of children under 5 years

\begin{tabular}{|c|c|c|}
\hline & OR & $P$ value \\
\hline \multicolumn{3}{|l|}{ "No education of mother" and "Country GDP per capita" } \\
\hline Low income countries with low health expenditure and high inequalities & 1.821 & 0.025 \\
\hline Middle income countries with low health expenditure and high inequalities & 1.368 & 0.075 \\
\hline Upper middle income countries with low health expenditure and high inequalities & Reference category & \\
\hline Low income countries with middle health expenditure and high inequalities & 1.872 & 0.026 \\
\hline Middle income countries with middle health expenditure and high inequalities & 1.382 & 0.087 \\
\hline Upper middle income countries with middle health expenditure and high inequalities & Reference category & \\
\hline Low income countries with upper health expenditure and high inequalities & 1.683 & 0.040 \\
\hline Middle income countries with upper health expenditure and high inequalities & 1.224 & 0.141 \\
\hline Upper middle income countries with upper health expenditure and high inequalities & Reference category & \\
\hline Low income countries with low health expenditure and low inequalities & 1.488 & 0.032 \\
\hline Middle income countries with low health expenditure and low inequalities & 1.143 & 0.198 \\
\hline Upper middle income countries with low health expenditure and low inequalities & Reference category & \\
\hline Low income countries with middle health expenditure and low inequalities & 1.533 & 0.031 \\
\hline Middle income countries with middle health expenditure and low inequalities & 1.186 & 0.287 \\
\hline Upper middle income countries with middle health expenditure and low inequalities & Reference category & \\
\hline Low income countries with upper health expenditure and low inequalities & 1.374 & 0.046 \\
\hline Middle income countries with upper health expenditure and low inequalities & 1.107 & 0.423 \\
\hline Upper middle income countries with upper health expenditure and low inequalities & Reference category & \\
\hline \multicolumn{3}{|l|}{ "Household wealth" and "Country GDP per capita" } \\
\hline Low income countries with low health expenditure and high inequalities & 0.994 & 0.046 \\
\hline Middle income countries with low health expenditure and high inequalities & 0.996 & 0.235 \\
\hline Upper middle income countries with low health expenditure and high inequalities & Reference category & \\
\hline Low income countries with middle health expenditure and high inequalities & 0.969 & 0.048 \\
\hline Middle income countries with middle health expenditure and high inequalities & 0.981 & 0.125 \\
\hline Upper middle income countries with middle health expenditure and high inequalities & Reference category & \\
\hline Low income countries with upper health expenditure and high inequalities & 0.980 & 0.050 \\
\hline Middle income countries with upper health expenditure and high inequalities & 0.987 & 0.257 \\
\hline Upper middle income countries with upper health expenditure and high inequalities & Reference category & \\
\hline Low income countries with low health expenditure and low inequalities & 0.979 & 0.049 \\
\hline Middle income countries with low health expenditure and low inequalities & 0.982 & 0.279 \\
\hline Upper middle income countries with low health expenditure and low inequalities & Reference category & \\
\hline Low income countries with middle health expenditure and low inequalities & 0.956 & 0.042 \\
\hline Middle income countries with middle health expenditure and low inequalities & 0.972 & 0.064 \\
\hline Upper middle income countries with middle health expenditure and low inequalities & Reference category & \\
\hline Low income countries with upper health expenditure and low inequalities & 0.966 & 0.045 \\
\hline Middle income countries with upper health expenditure and low inequalities & 0.975 & 0.128 \\
\hline Upper middle income countries with upper health expenditure and low inequalities & Reference category & \\
\hline
\end{tabular}

found that low income and inequality at the country level, but not health expenditure, were associated with diarrheal disease. These findings suggest that poverty and inequality are associated with child health. Children who live in developing countries with greater per capita
GDP and lower inequality were less likely to develop diarrhea. These findings support the importance of fundamental determinants of health, such as per capita GDP and income inequalities, promulgated by social epidemiology [22]. The results could be explained by 
Bronfenbrenner's ecological model, which considers the importance of macro level conditions on individual wellbeing [12].

On the contrary, diarrheal disease was not associated with a country's health expenditure. It is important to interpret this finding considering that child health in general is not improved exclusively by the amount of money a country invests in health. Establishing an association between health expenditure and health is not easy, since it depends on the characteristics of the expenditure as well as on many factors associated with the health outcomes, and it was not possible to consider all of these in this paper [23].

The associations of some of the well-known determinants of health, such as immunization status, maternal education, and household wealth with diarrhea, were considerably affected by country characteristics. The country variables included in the analysis could only partially explain the effect the country level exerts over the relationship of diarrhea with lack of maternal education and household wealth. In richer countries, lack of maternal education and household poverty were not as important as they were in poorer countries. In the same direction, the lack of maternal education had a greater association with diarrheal disease in countries with larger inequality.

These findings support the importance of healthy environments on child health, even if these environments seem distant to the child [24]. The characteristics of the country in which an individual develops, molds him in a several different ways from culture and identity to constraints and possibilities. Poor countries do not have the resources and infrastructure to adequately protect their nationals. Similarly, unequal countries pose a burden on their citizens who perceive the income distribution as unfair. Health interventions often focus on individuallevel as a unit of analysis and treat all countries as equal, while the interventions should be tailored to the country's characteristics. According to our results, inequalities and poverty at the country level should be fought in order to improve child health. Particular consideration should be given to poor and unequal developing countries where poor and uneducated women should receive special programs to prevent child disease.

In this study, child-related characteristics associated with diarrhea were as follows. (1) Gender: Compared to girls, boys had $9 \%$ higher odds of developing diarrhea. This is consistent with the results of another study on diarrhea epidemiology [24]. (2) Age: Each additional month of age decreased on average by $2 \%$ the odds of having diarrhea, and this finding supports what has been reported in the literature [24]. (3) Immunization: Compared with children with complete immunization, those with an incomplete immunization status had $22 \%$ higher odds of developing diarrhea. However, this DHS did not assess vaccination against rotavirus, which could reduce even more the burden of the disease in young children [25, 26]. (4) Birthweight: children born $\geq 2,500 \mathrm{~g}$ had $14 \%$ less probability of having diarrhea. A low birthweight could imply maternal nutritional deficiency that has been associated with diarrhea and child mortality [27, 28]. In a 2005-2007 study on diarrhea-related child mortality in the USA, Mehal et al. concluded that $86 \%$ of the children who died had a low birthweight [5]. (5) Breast feeding: Bivariate correlation analysis showed a negative association between diarrhea and breast feeding, as has been established in the literature [29]. However, this association was not seen on multivariable models, probably because the mothers had reported the duration of breastfeeding, but not information on simultaneous complementary feeding, and because other variables in the model may have interfered with this association.

The maternal characteristics associated with diarrhea in this study were as follows. (1) Age: Younger mothers reported diarrhea more frequently than older ones, which could be explained in part by the younger mothers' lack of experience with child care [30]. (2) Maternal education: Compared with children of highly educated mothers, the children of mothers without formal education, with elementary education and with high school education had 42, 45 and $29 \%$ higher odds of having diarrhea, respectively. These findings confirm the results reported in medical literature [31]. (3) Occupation: Children of working mothers had $14 \%$ higher odds to have diarrhea than those of mothers who did not work. This finding supports those who affirm that a mother's work is detrimental to her child's well-being. It is probable that the mothers' absence from the household, along with poor social support had negative effects on child health [32, 33]. (4) Planned pregnancy: We found that the children who were a result of a planned pregnancy had $29 \%$ smaller odds of developing diarrhea than did children who were the result of an unplanned pregnancy. Children from unplanned pregnancies are less likely to receive adequate care [34]. Additionally, family planning decreases the risk of low birth weight [35], which is a known risk factor for diarrhea [5].

The household characteristics associated with diarrhea in this study were as follows. (1) Number of household members: This was associated with diarrhea on bivariate correlation but not on the multivariable model, probably due to other household conditions included in the present study that may be associated with overcrowding. (2) Type of residence: Bivariate correlation showed that children from rural areas were more likely to present with diarrhea, as described previously in the literature [36]. This association disappeared on multivariable models, probably due to the introduction of household wealth in 
the multivariable models. (3) Nuclear families: Children from nuclear families had $5 \%$ smaller odds of developing diarrhea than did children from non-nuclear families. This outcome is probably secondary to the described effect of social stability that a nuclear family structure has on child health [37]. (4) Sanitation: Adequate sanitation conditions helped prevent diarrhea. It has been estimated that approximately $88 \%$ of diarrhea-induced deaths in the world are attributable to inadequate water supplies, poor hygiene and unsanitary conditions [38]. Moreover, most of these deaths $(84 \%)$ occur in children and in developing countries [39]. (5) Wealth index: As expected, children from wealthier families had a lower probability of developing diarrhea. This result is consistent with what has been reported in the literature $[22,40]$.

\section{Limitations}

DHS have great advantages such as the quality, comparability and representativeness of the information. Nevertheless, the study has some important limitations. First, its cross-sectional nature does not allow establishment of causality. Second, the DHS questionnaires were not performed simultaneously in every country. Although our analysis did not change after controlling for year of survey, social conditions are dynamic and tend to change over time, therefore some differences could be expected. Third, data was collected exclusively from the mother, and while they tend to be the best historian concerning their child's history, some recall bias is likely. Fourth, the variable definitions are limited by the information available in the DHS. Finally, the large sample size contributes to an over-power analysis that could detect minimal effect sizes, and these effect sizes could be the result of slight biases in the sampling process.

\section{Conclusions}

Diarrhea is a major health problem worldwide, particularly in children living in developing countries. The study of fundamental determinants of health, "determinants of determinants", could be the foundation upon which we formulate promising solutions that are tailored to the reality of populations and the environment they are immersed. This study explored the association of per capita GDP, income inequalities (Gini coefficient) and health expenditure with diarrheal disease in a large, multinational population adjusting by individual, family and household characteristics, using a multilevel design.

We found a clear association between socio-economic factors and the onset of diarrheal disease in children under 5 years old from developing countries. The factors associated with a greater risk of developing diarrhea are low maternal education, mother employment, poverty and inequality. The factors associated with a lower risk of diarrheal disease are female gender, older children, complete immunization status and normal birthweight. The maternal protective factors were older age and planned pregnancy. The household and country protective factors were a nuclear family structure, appropriate sanitation and greater wealth of the household.

Economic development and inequalities at the country level are contributing to the onset of diarrhea, regardless of children, maternal or household characteristics. The individual features associated with the onset of diarrhea are directly affected by the country's inequality and poverty. Additionally, health expenditure does not seem to play a key role in the onset of the disease. Hence, in order to effectively address diarrheal disease and child wellbeing in general, these country features (per capita GDP and inequalities) should be taken into consideration.

These results are helpful for initiatives such as the WHO's Child Health Epidemiology Reference Group in determining factors associated with child morbidity and possible interventions [41].

\section{Appendix 1. Literature search strategy}

The review was conducted searching in two electronic databases (PubMed and EMBASE). 788 studies, written in English and Spanish, were identified from January 1st 2003 until December 31 2014. We used the following $\mathrm{MeSH}$ words in PubMed.

\#1. MeSH Headings: "Infant"[Mesh] OR "Infant, Newborn"[Mesh] OR "Child, Preschool"[Mesh] OR "Child" [Mesh]

\#2. MeSH Subheadings: "Diarrhea/epidemiology"[Mesh] OR "Diarrhea/prevention and control" [Mesh] OR "Diarrhea/complications"[Mesh] "Diarrhea, Infantile/epidemiology"[Mesh] OR “Diarrhea, Infantile/mortality"[Mesh] OR "Diarrhea, Infantile/prevention and control"[Mesh] OR "Diarrhea, Infantile/complications"[Mesh] OR "Gastroenteritis/prevention and control"[Mesh]

\#3. MeSH Headings and Subheadings: "Breast Feeding" [Mesh] OR "Risk Factors"[Mesh] OR "Poverty"[Mesh] OR "Developed Countries"[Mesh] OR "Developing Countries"[Mesh] OR "Malnutrition/complications"[Mesh] OR "Malnutrition/prevention and control"[Mesh] OR "Parents/education"[Mesh] OR "Delivery of Health Care/utilization"[Mesh] OR "Health Status Disparities"[Mesh]

\#4. \#1 AND \#2 AND \#3

The key words were slightly adapted for EMBASE.

Duplicate records were removed, leaving 485 papers. Subsequently, we screened and evaluated the articles reading their titles and abstracts. After this process we had 94 potentially useful studies based on their assessment of determinants of diarrhea. We read all these articles and picked the best ones to reference in our paper.

After cleaning the data, an additional literature review was done in order to explore the association of each of the available variables with diarrheal disease. 
Appendix 2. Specifications for this Bernoulli HLM2 run

The maximum number of level- 1 units $=348,706$

The maximum number of level- 2 units $=40$

The maximum number of micro iterations $=14$

Method of estimation: full PQL

Maximum number of macro iterations $=100$

Distribution at Level-1: Bernoulli

Weighting Specification

\begin{tabular}{llll}
\hline & Weighting? & Weight Variable & Normalized? \\
\hline Level 1 & Yes & SWEIGHT & yes \\
Level 2 & Yes & WEIGHT2 & yes \\
Precision & No & & \\
\hline
\end{tabular}

The outcome variable is Diarrhea

Summary of the model specified

\section{Level-1 model}

$\operatorname{Prob}($ DIARRHEAij $=1 \mid \beta \mathrm{j})=\phi \mathrm{ij}$

$\log [\phi i \mathrm{ij} /(1-\phi \mathrm{ij})]=\eta \mathrm{ij}$

$\eta \mathrm{ij}=\beta 0 \mathrm{j}+\beta 1 \mathrm{j}^{*}($ Female sex $\mathrm{ij})+\beta 2 \mathrm{j}^{*}($ Age of the child $\mathrm{ij})$

$+\beta 3 j^{*}($ Immunizations $\mathrm{ij})+\beta 4 \mathrm{j}^{*}$ (Normal weight at birth $\left.\mathrm{ij}\right)$

$+\beta 5)^{* *}($ No weighed at birth $\left.\mathrm{ij})+\beta 6\right)^{* *}$ (Duration of breastfeeding

ij) $+\beta 7 j^{*}($ Age of the mother ij $)+\beta 8 j^{*}($ No education of the mother $j)+\beta 9 j *($ Elementary education ij $)+\beta 10 j^{* *}($ High school education $\mathrm{ij})+\beta 11 \mathrm{j} *($ Employment $\mathrm{ij})+\beta 12 \mathrm{j} *($ Planned pregnancy $\mathrm{ij})+\beta 13 \mathrm{j}^{*}($ Nuclear family $\mathrm{jj})+\beta 14 \mathrm{j}^{*}($ Urban residence ij $)+\beta 15 j^{*}($ Wealth Index $\mathrm{ij})+\beta 16 \mathrm{j}^{*}($ Survey year ij $)$

\section{Level-2 model}

$\beta 0 \mathrm{j}=\gamma 00+\gamma 01 *($ Low income $\mathrm{j})+\gamma 02 *($ Middle income $\mathrm{j})+$ $\gamma 03^{*}($ Inequality $\mathrm{j})+\gamma 04 *($ Middle health expenditure $\mathrm{j})+$ $\gamma 05^{*}($ High health expenditure $\mathrm{j})+\mathrm{u} 0 \mathrm{j}$
$\beta 1 \mathrm{j}=\gamma 10$
$\beta 2 j=\gamma 20$
$\beta 3 \mathbf{j}=\gamma 30$
$\beta 4 \mathrm{j}=\gamma 40$
$\beta 5 \mathrm{j}=\gamma 50$
$\beta 6 \mathbf{j}=\gamma 60$
$\beta 7 j=\gamma 70$

$\beta 8 j=\gamma 80+\gamma 81^{*}($ Low income $j)+\gamma 82^{*}($ Middle income $j)+$ $\gamma 83 *$ (Inequality $\mathrm{j})+\gamma 84 *$ (Middle health expenditure $\mathrm{j})+$ $\gamma 85 \%($ High health expenditure $\mathrm{j})+\mathrm{u} 8 \mathrm{j}$

$\beta 9 j=\gamma 90$

$\beta 10 j=\gamma 100$

$\beta 11 j=\gamma 110$

$\beta 12 j=\gamma 120$

$\beta 13 \mathbf{j}=\gamma 130$

$\beta 14 j=\gamma 140$ $\beta 15 j=\gamma 150 \gamma 151 *($ Low income $j)+\gamma 152 *$ (Middle income j) $+\gamma 153^{*}$ (Inequality j) $+\gamma 154 *$ (Middle health expenditure $\mathrm{j})+\gamma 155^{*}($ High health expenditure $\mathrm{j})+\mathrm{u} 15 \mathrm{j}$ $\beta 16 \mathbf{j}=\gamma 160$

Immunizations, No maternal education and Wealth index have been centered around the group mean.

All other variables have been centered around the grand mean.

Level 2 variables have been centered around the grand mean.

\section{Abbreviations \\ BMI: Body mass index; Cl: Confidence interval; DHS: Demographic and health survey; GDP: Gross domestic product; ICC: Intra-class correlations; IOR: Interval odd ratios; MOR: Median odd ratios; OR: Odds ratio; WB: World Bank; WHO: World Health Organization.}

\section{Competing interests}

The authors declare that they have no competing interests.

\section{Authors' contributions}

AMPR: conceptualized and designed the study, conducted the statistical analysis, supervised and revised the drafting of the manuscript, and approved the final manuscript as submitted. CZA: carried out the initial analysis, reviewed and revised the manuscript, and approved the final manuscript as submitted. AHM: helped to conceptualize and design the study, drafted the initial manuscript, and approved the final manuscript as submitted. AMRS: helped to contextualize and design the study, revised the analysis suggesting relevant changes, revised the draft and approved the final manuscript as submitted. AVvM: helped to contextualize and design the study, revised the analysis suggesting relevant changes, revised the draft and approved the final manuscript as submitted.

\section{Acknowledgements}

The authors would like to acknowledge Milciades Ibañez, Rafael Tovar and Jose Moreno for their statistical advice, as well as Macro International for providing the individual country datasets for analysis.

Universidad del Rosario provided funding for this study. The Public Health Research Group funded the participation of AMPR, CZA and AHM, while the Clinical Research Group funded de participation of AMRS and AVVM.

\section{Financial disclosure}

The authors have no financial relationships to this article to disclose.

Received: 26 May 2014 Accepted: 4 August 2015

Published online: 21 August 2015

\section{References}

1. United Nations Children's Fund. The State of the World's Children 2014. New York: Every Child Counts; 2014

2. You D, New JR, Wardlaw T on behalf of the United Nations Inter-agency Group for Child Mortality Estimation. Levels and Trends in Child Mortality. New York: The United Nations Children's Fund; 2012.

3. United Nations U. The Millenium Development Goals Report. New York: United Nations; 2010.

4. Cheng A, McDonald J, Thielman N. Infectious diarrhea in developed and developing countries. Journal of Clinical Gastroenterology. 2005;39(9):757-73.

5. Mehal JM, Esposito DH, Holman RC, Tate JE, Callinan LS, Parashar UD. Risk factors for diarrhea-associated infant mortality in the United States, 2005-2007. Pediatr Infect Dis J. 2012;31(7):717-21.

6. Dewey KG, Mayers DR. Early child growth: how do nutrition and infection interact? Matern Child Nutr. 2011:7 Suppl 3:129-42.

7. Fischer-Walker C, Aryee M, Boschi-Pinto C, Black R. Estimating diarrhea mortality among young children in low and middle income countries. PLoS ONE. 2012;7(1):e29151.

8. Wang Y, Zhu J, He C, Li X, Miao L, Liang J. Geographical disparities of infant mortality in rural China. Arch Dis Child Fetal Neonatal Ed. 2012;97(4):F285-290. 
9. Kosek M, Bern C, Guerrant RL. The global burden of diarrhoeal disease, as estimated from studies published between 1992 and 2000. Bull World Health Organ. 2003;81(3):197-204

10. Mølbak K, Jensen $H$, Ingholt L, Aaby P. Risk factors for diarrheal disease incidence in early childhood: a community cohort study from Guinea-Bissau. Am J Epidemiol. 1997;146(3):273-82.

11. Karim AS, Akhter S, Rahman MA, Nazir MF. Risk factors of persistent diarrhea in children below five years of age. Indian J Gastroenterol. 2001:20(2):59-61.

12. Bronfenbrenner U. Toward an experimental ecology of human development. The American Psychologist. 1977;84(2):7-11.

13. Fuller JA, Clasen T, Heijnen M, Eisenberg JN. Shared sanitation and the prevalence of diarrhea in young children: evidence from 51 countries, 2001-2011. Am J Trop Med Hyg. 2014;91(1):173-80.

14. The Demographic and Health Survey Program [Internet]. Rockville MD: The DHS program [cited 2014 May 13]. Available from: http:/www.dhsprogram.com/.

15. The World Bank Data [Internet]. Washington DC: The World Bank; 2014 [cited 2014 May 13]. Available from: http://data.worldbank.org/.

16. World Health Organization W, United Nations Children's Fund U. Global Water Supply and Sanitation Assessment 2000 Report. USA: WHO/UNICEF; 2000.

17. Sellstrom E, Bremberg S. The significance of neighbourhood context to child and adolescent health and well-being: a systematic review of multilevel studies. Scandinavian Journal of Public Health. 2006;34:544-54

18. Raudenbush SW, Bryk AS. Hierarchical Linear Models (Second Edition). Thousand Oaks: Sage Publications; 2002.

19. Guo G, Zhao H. Multievel modeling for binary data. Annu Rev Sociol. 2000;26:441-62.

20. Larsen K, Merlo J. Appropriate assessment of neighborhood effects on individual health: integrating random and fixed effects in multilevel logistic regression. American journal of epidemiology. 2005;161(1):81-8.

21. Merlo J, Chaix B, Ohlsson H, Beckman A, Johnell K, Hjerpe $P$, et al. A brief conceptual tutorial of multilevel analysis in social epidemiology: using measures of clustering in multilevel logistic regression to investigate contextual phenomena. Journal of epidemiology and community health. 2006:60(4):290-7

22. Berkman L, Kawachi I. Social epidemiology. New York: Oxford University Press; 2000.

23. Nixon J, Ulmann P. The relationship between health care expenditure and health outcomes. Evidence and caveats for a causal link. Eur J Health Econ. 2006;7(1):7-18

24. Fischer Walker $\mathrm{CL}$, Perin J, Aryee MJ, Boschi-Pinto C, Black RE. Diarrhea incidence in low- and middle-income countries in 1990 and 2010: a systematic review. BMC Public Health. 2012;12:220

25. Parashar UD, Burton A, Lanata C, Boschi-Pinto C, Shibuya K, Steele D, et al. Global mortality associated with rotavirus disease among children in 2004. J Infect Dis. 2009;200 Suppl 1:S9-S15.

26. Cortes JE, Curns AT, Tate JE, Cortese MM, Patel MM, Zhou F, et al. Rotavirus vaccine and health care utilization for diarrhea in U.S. children. N Engl J Med. 2011:365(12):1108-17.

27. Wu G, Bazer FW, Cudd TA, Meininger CJ, Spencer TE. Maternal nutrition and fetal development. J Nutr. 2004;134(9):2169-72.

28. Belkacemi L, Nelson DM, Desai M, Ross MG. Maternal undernutrition influences placental-fetal development. Biol Reprod. 2010;83(3):325-31.

29. Lamberti L, Fischer Walker C, Noiman A, Victora C, Black R. Breast feeding and the risk for diarrhea morbidity and mortality. BMC Public Health. 2011;11.

30. Canning D, Finlay J, Ozaltin E. The association of maternal age with infant mortality, child anthropometric failure, diarrhoea and anaemia for first births: evidence from 55 low- and middle-income countries. BMJ Open. 2011;1(2):e000226.

31. Webb AL, Ramakrishnan U, Stein AD, Sellen DW, Merchant M, Martorell R. Greater years of maternal schooling and higher scores on academic achievement tests are independently associated with improved management of child diarrhea by rural Guatemalan mothers. Matern Child Health J. 2010;14(5):799-806.

32. Baydar N, Brooks-Gunn J. Effects of maternal employment and child-care arrangements on preschoolers' cognitive and behavioral outcomes: evidence from the Children of the National Longitudinal Survey of Youth. Development and Psychopathology. 1991;27(6):932-45.

33. Berger L, Hill J, Waldfogel J. Maternity leave, early maternal employment and child health and development in the US. Economic Journal. 2005;115(501):29-47.
34. Cheng D, Schwarz EB, Douglas E, Horon I. Unintended pregnancy and associated maternal preconception, prenatal and postpartum behaviors. Contraception. 2009;79(3):194-8.

35. Conde-Agudelo A, Rosas-Bermudez A, Kafury-Goeta AC. Birth spacing and risk of adverse perinatal outcomes: a meta-analysis. JAMA. 2006;295(15):1809-23.

36. El-Gilany AH, Hammad S. Epidemiology of diarrhoeal diseases among children under age 5 years in Dakahlia, Egypt. East Mediterr Health J. 2005;11(4):762-75.

37. Blackwell D. Family Structure and Children's Health in the United States: Findings from the National Health Interview Survey, 2001-2007. 2010.

38. World Health Organization W. UN-Water Global Annual Assessment of Sanitation and Drinking-Water (GLAAS) 2010: Targeting Resources for Better Results. Switzerland: WHO; 2010.

39. World Health Organization W. Global Health Risks: Mortality and Burden of Disease Attributable to Selected Major Risks. France: WHO; 2009.

40. Wilunda C. Factors associated with diarrhea and acute respiratory infections among children less than 5 years old in Thailand: a secondary analysis of Thailand multiple indicator cluster survey 2006. Thailand: Chulalongkorn University; 2008

41. Child Health Epidemiology Reference Group [Internet]. Baltimore, MD: Child Health Epidemiology Reference Group [cited 2014 Dec 23]. Available from: http://cherg.org/main.html.

\section{Submit your next manuscript to BioMed Central and take full advantage of:}

- Convenient online submission

- Thorough peer review

- No space constraints or color figure charges

- Immediate publication on acceptance

- Inclusion in PubMed, CAS, Scopus and Google Scholar

- Research which is freely available for redistribution 